\title{
Duchenne Muscular Dystrophy
}

National Cancer Institute

\section{Source}

National Cancer Institute. Duchenne Muscular Dystrophy. NCI Thesaurus. Code C75482.

An X-linked inherited disorder caused by mutations in the DMD gene found on the $X$ chromosome. It is characterized by rapidly progressing muscle weakness and muscle atrophy initially involving the lower extremities and eventually affecting the whole body. It affects males whereas females can be carriers. The symptoms start before the age of six and may appear at infancy. 